\title{
Problemática de Organização do Turismo enquanto Habilitação Profissional e Área de Pós-Graduação
}

\section{Tupã Gomes Corrêa ${ }^{1}$}

RESUMO:Analisa a problemática de organização do Turismo enquanto habilitação profissional e área dc pós-graduação na Escola de Comunicações e Artes da Universidade de São Paulo, em um departamento que abriga duas outras áreas: Relações Públicas e Publicidade.

PALAVRAS-CHAVES: Ensino em Turismo; formação superior; graduação; pós-graduação; Universidade de São Paulo; São Paulo; Brasil.

ABSTRACT: This article analyzes the problems arouse in organizing Tourism as a professional degree and post graduation area en the School of Arts and Communications of the University of São Paulo, in Department which aggregates two more areas: Public Relations and Publicity.

KEY WORDS:Teaching of tourism; high school degree; post graduation; University of São Paulo; Brazil.

Relações Públicas, Publicidade, Promoção de Vendas, Turismo. Velhas alianças de um negócio duradouro. Dimensões modernas de hábitos antigos. Não há novidade alguma nessas discussões, pelo menos para o grupo de pesquisadores e professores que, há mais de duas décadas, sustenta este que é uns dos primeiros cursos superiores em turismo implantado no país. Tem sido principalmente na Universidade de São Paulo que discussões desse gênero vêm contribuindo para manter e ampliar relações entre áreas que são aparentemente tão distintas quanto essas.

I. Professor Titular do Departamento de Relações Públicas, Propaganda e Turismo da Escola de Comunicações e Artes da USP. Vice-Diretor da ECA-USP.

End. para corresp.: ECA-USP. Cidade Universitária “Armando de Salles Oliveira”. Av. Prof. Lúcio Martins Rodrigues, 443 - 05508-900 - São Paulo, SP, Brasil. Fax : (011) 814-4764. 
Também não seria para menos. Convivendo o próprio curso com os de publicidade e relações públicas todos esses anos, acabaria ele mesmo se convicrtendo espontaneamente no principal clo de articulação entre clas. Com isto, a cada dia justifica e consolida a interrelação de áreas tão distintas quanto importantes dentro e fora da universidade, seja no campo da administração ou da gerência de negócios, seja no do marketing ou da comunicação.

O entendimento hoje de que turismo é uma atividade própria da adminis. tração, voltada sobretudo para a prestação de serviços de transporte, alojamento restauração e lazer, contribuiu para o alicerçamento de uma idéia específica accrca da natureza dessa atividade. De igual modo, outras especialidades, como a divulgação e a promoção de vendas, quando interagem por seu intermédio, o faz.em de sorte a justificar a necessidade que o turismo também tem de socorrer-sc, cm nivel de assessoria ou consultoria, de outras atividades profissionais.

As fronteiras entre turismo e relações públicas, pelo menos na Universidade de São Paulo, durante um certo período, por conta das pessoas que então sc ocupavam de um e outro curso, chegaram a se confundir. Pode-se mesmo dizer que os efeitos dessa "confusão" duraram muitos anos, impregnando um c outro campo de trabalho de atributos que chegaram praticamente aos diferentes campos conceituais

Com o passar dos anos, porém, tudo acabaria se ajustando, sem prejuízo para nenhuma das áreas. Hoje, embora a colaboração docente muitas vezes ocorra em campos trans e multidisciplinares, verificando-se com frequiência a presença de professores de um em outro curso, longe de confundir-se o campo conceitual, traduz-se a colaboração em significativa troca de resultados conjuntos, que acabam se tornando altamente positivos para a formação profissional no departamento onde esta ocorre.

A organização da área, um tanto distante da comunicação, em um departamento que também abriga as habilitações de relações públicas e de publicidade conduziu a estruturas curriculares absolutamente simbióticas, incentivando (c por vezes até mesmo obrigando) à convivência de interesses quase tão diversos quanto opostos. Se num primeiro momento todos foram levados a descobrir modos do superação de conflitos, em outros emergiu a principal característica dos profissionais que ainda hoje atuam em conjunto: a capacidade de harmonizar distinções, formulando criativas maneiras de um convívio profissional amistoso e produtivo

Mas, que continuarão a fazer juntas, ainda hoje, coisas tão diferentes uma da outra, como o turismo e as relações públicas? Ou, a publicidade e o turismo?

Deve-se, em primeiro lugar, lembrar o tempo em que foi iniciada a discussão para instituir-se o curso de turismo na Escola de Comunicações e Artes da USP. Durante algum tempo, um grupo de pessoas debateu a idéia, ofereceu sugestões c tentou, sem sucesso, um consenso que previa a criação da nova habilitação profissional.

As pessoas que então integravam o grupo que se ocupava da instituição do novo curso, ou que apenas se dedicaram a contribuir transitoriamente para com elc. acabaram convergindo para a arrojada iniciativa da criação dessa graduação, que em tudo era nova e diferentc, numa universidade tão tradicional quanto a USP. O quc. em si, acabou se transformando num problema de raiz, sedimentando-se como característica atć mesmo da cstrutura curricular logo a seguir formulada c que permanece atć os dias de hoje.

Nomes como o do jesuíta canadense Lambert Bovi, do engenheiro Mario Carlos Beni, da pedagoga Nelly de Camargo, do antropólogo Egon Schaden, do geógrafo Antonio Rocha Penteado, do arquiteto Nestor Goulart Reis, do advogado Teobaldo Andrade, do publicitário Otto Scherb, do matemático Oswaldo Sangiorgi, do economista Silvio Borges dos Reis, do historiador Virgílio Noya Pinto, da psicóloga Vera Lagoa c da socióloga Sarah Bacal figuram numa galeria de incontáveis participaçõcs quc, de algum modo, contribuíram dirctamentc para a efetivação do projeto do referido curso.

É claro que na sequiência haveria mais nomes, de não menor relcvo, de outros professores da Universidade de São Paulo que, baseados na Escola de Comunicaçõcs c Artes (mais precisamente no então departamento de relações públicas c propaganda), delincariam a primeira estrutura curricular c o primeiro corpo docentc do curso cm questão.

Institucionalmente, no entanto, a ser comprovado pelos registros das primeiras manifestações $\mathrm{cm}$ reuniões que se realizaram fora da ECA a respeito, a universidade demonstrava um certo temor em adotar curso tão fora do cixo que então predominava entre suas cstruturas tradicionais. Embora na década de setenta já houvesse excmplos de grandes universidades americanas ou curopéias que ostentavam entre seus currículos também o de turismo, havia internamente un nítido desconforto com relação a ele.

Dentre os cursos existentes na época, os de maior relevo situavam-se na Espanha. Mesmo no Brasil já cxistia um, criado por instituição privada de cnsino supcrior, a Faculdade Anhembi. Mas se no caso local a experiência cra insuficientc numericamentc, os cxemplos estrangeiros parecem ter contribuido bastante para a decisão da USP, no sentido de também instituir uma graduação nessa área.

Embora adotando-o cntre as estruturas curriculares que compunham na época o espectro das demais, a Universidade de São Paulo nunca chegou realmentc a assimilar um curso que, no dizer de alguns, por vezes

técnico do que para um superior propriamente dito". É certo que sempre houve muita desinformação e muito preconceito contra o curso, claro, mas essa predisposição negativa parece ter sido gerada numa cultura própria, cujo principal rellexo pode ser constatado na forma mediante a qual se vinculou essa habilitação na universidade: num instituto de artes e de comunicação.

A culpa pela desinformação também deve ser debitada $\mathrm{cm}$ grande partc aos integrantes da área que, ao longo do tempo, priorisariam o processo de sua incorporação às convenções acadêmicas de uma universidade tradicional, $\mathrm{cm}$ detrimento do esforço de divulgação e csclarecimento do novo campo, que deveria ter se desenvolvido desde o início da criação do curso c do respectivo corpo docente. Pois, se de um lado cra importante acelerar a assimilação do ambiente $\mathrm{cm}$ que os profissionais de turismo passavam a trabalhar, de outro era imprescindivel que os 
integrantes que aí já se encontravam também fossem supridos de informaçòcs a respeito de uma área de crescente importância no mundo contemporâneo.

As manifestações negativas não partiam necessariamente do departamento $\mathrm{cm}$ que, desde o início, vinculou-se o turismo. Raramente, da própria cscola. O que vinha a ser comum cra que clas fossem percebidas junto a departamentos e institutos mais tradicionais, coincidindo com uma forma de preconccito acadêmico cxistente $\mathrm{cm}$ qualquer universidade com as mesmas características da Universidade de São Paulo. Isto porque instituições desse porte costumam ser largamente notórias partir de suas árcas de cxcelência, com sólida definição c arraigada tradição científica. Nelas, quase sempre, coisas novas costumam ser observadas como "cxperimentação", ou como novidades de duvidosa justificação.

Com o passar do tempo, pode-se verificar que apesar do arrefecimento das críticas (as quais, por mais construtivas que tenham sido, sempre resultaram $\mathrm{cm}$ grande prejuizo para a própria universidade), de uma consentida trégua, ou de uma tolerância institucional que permitiu a consolidação do curso enquanto habilitação profissional de nível superior, ainda permanece a dúvida quanto ao papel e à natureza cxplicitamente acadêmica da área

Alguns fatos que ocorreram nos últ imos tempos, todavia, são dignos de nota. Eles configuram, cm muito, o espírito que ainda permanece $\mathrm{cm}$ alguns setores da universidade com relação ao curso de graduação, à área de pós-graduação c aos professores que integram todo esse contexto. O mais significativo deles diz respeito ao congresso "Sol e Território", realizado $\mathrm{cm} 1995$ pelo departamento de geografía da USP

À época cm que circularam as primeiras notícias sobre o aludido evento, $\mathrm{cm}$ fins de 1994, éramos ainda o chefe do departamento de relações públicas, propaganda e turismo. Na ocasião, um grupo de docentes do curso de turismo. munido do programa preliminar do congresso, procuroul-nos para discutir a situação de uma reunião de estudos sobre tema diretamente relacionado ao departamento, porém organizado fora dele, numa promoção de área de estudo específica.

Em que pese a circunstância da interpelação, cujosatores (da parte do curso de turismo) encontravam-se tanto tensos quanto preocupados $\mathrm{cm}$ decorrência de um pretenso risco à sua reputação acadêmica, tomamos a iniciativa de primeiro fazc com que entendessem a lógica universitária. Pois, como se sabe, este é o espaço cm que ninguém pode ser impedido de estudar. De igual modo, os agentes desencadeadores daquela situação (os colegas do departamento de geografia) também estariam na mesma posição, fosse o processo deflagrado $\mathrm{cm}$ sentido inverso.

Se, de idêntica mancira, não se deve interferir $\mathrm{cm}$ iniciativa semelhante do departamento de geografia, ao realizar cvento sobre turismo, também não se derc atrapalhar a do curso de turismo cm promover reunião sobre geografia. Como, a liás. seria fato corrente a seguir, quando da reunião internacional sobre marketing turístico, quando se envolveu, alćm dos convidados que chegaram do Exterior. uII cxpressivo número de professores do próprio departamento de administração
É bem verdade que há uma questão ćtica c uma questão de estilo na organização desse gênero de evento, caracterizado sobretudo pela interface de áreas, ou convexão de conteúdos. Em nenhum momento, por cremplo, deve o curso de publicidade realizar um simpósio sobre propaganda farmacêutica sem o concurso das áreas de farmácia na universidade. Ou, quem sabe, um seminário sobre ações corporativas nos conglomerados bancários, pelo curso de relações públicas, sem envolver áreas especificas $\mathrm{cm}$ marketing e administração.

Se de um lado o estilo de iniciativas desse tipo de evento impõe discussões públicas sobre o estado dos estudos a respeito, de outro a ética das relações acadêmicas implica necessariamente a co-participação de áreas afins. Como, finalmente, acabou acontecendo no caso do congresso "Sol c Território".

Todavia, a simples ocorrência do episódio aqui mencionado serve para demonstrar que ainda cxiste muita desinformação a respeito da função e do míster de um curso como o de turismona universidade. Não seria, com certeza, o descrétido profissional no meio universitário, a colocar em risco a reputação acadêmica de professores de outro departamento, pelo simplesfato de se assumir, cm determinado momento, o objet o de seu trabalho. Como também não seria a situação de se colocar em discussão a natureza do seu trabalho. O que importa, isto sim, ć compreender o alcance $\mathrm{e}$ a importância desse trabalho no espaço onde ele efetivamente reflete: o próprio mercado.

E claro que dentro da universidade, notadamente em áreas não tão próximas assim da atuação profissional, $\mathrm{tem}$ sido comum a crítica ao mercado como sendo cle, por si, o responsável a todo tipo de efeito nocivo que se abate contra a sociedade. $\mathrm{E}$, por csta razão simplista c pouco inteligente, tem sido comum imaginar que todos aqueles que se aproximam de objetos de estudo que envolvem os mecanismos de produção de bens ou serviços, aos sistemas de trocas, a promoção ao consumo e os efeitos desse processo no ser humano, devam ser, necessariamente, comprometidos com objetivos socialmente inaceitáveis.

O departamento de relações públicas, propaganda e turismo, desde a sua origem (que remonta à criação da antiga Escola de Comunicações Culturais da USP), cnfrenta restrições à postura absolutamente ralista da maior parte do seu corpodocentena condução das áreas que lhe sãoafetas, mediante o desenvolvimento de pesquisas que se voltam, em primeiro lugar, ao aprimoramento dos respectivos mercados. De igual sorte, traduzindo uma preocupação para com a ética que circunda as relações de troca.

Pode-se dizer, de um modo amplo, que várias são as atividades importantes, que interferem no processo de modo decisivo como instnumento de compreensão, planejamento e trabalho no turismo. Entre outros, além da geografia e da história, cncontram-se a cconomia, a psicologia, a engenharia, a arquitetura, a patrimoniação, a restauração, o marketing e a administração propriamente dita. Como se pode verificar a seguir.

- Geografia-instnumentoparao plancjamentodeusodoscspaços fisicosa seremexplorados e dos efeitos que essa exploração pode resultar sobre as respectivas populą̧̃es. 
- História - instrumento para o plancjamento da ações turísticas, levando cm conta a origem cultural dos cspaços cxplorados.

- Economia - instrumento que permite o plancjamento da cxploração turística con base nos dados decorrentes de demanda c oferta, alćm de outras quantificações importantes no deslocamento, acomodação, suprimento, entretenimento c laze dos volumes de turistas, a partir de sua capacidade de consumo dos serviços disponiveis.

- Psicologia - instrumento que torna possivel conhecer c cxercer técnicas de motivação c, conseqüentemente, análise das reações do usuário do senviço turistico, com o propósito de melhor adequá-lo a suas cxpectativas

- Engenharia - instrumento destinado ao aparelhamento infra-estrutural do turis mo, como sistemas viários e de navegação (aćrea, terrestre, marítima, fluvial lacustre), sistcmas de transporte c recepção, c outros sistemas de edificação.

- Arquitetura - instrumento voltado ao planejamento das edificações específicas de alojamento, entretenimento c lazer, alćm dos espaços complementares e estratégicos, como hotćis, cassinos, bares, boates, lanchonetes, restaurantes, hospitais, centros de lazer, centros de compras, centros culturais, centros de convenção, cxposição, fciras ctc.

- Patrimoniação - instrumento que permite conhecer c planejar a utilização de espaços que compreendem bens históricos, culturais ou naturais pela cxploração turistica.

- Restauração - instrumento que se volta à cxploração da subsistência alimentar do turista de maneira adequada e que justifique a ocasião, por padrões de estilo, os serviços demandados.

- Marketing - instrumento que torna possivel a promoção, o incremento e 0 incentivo dos serviços turísticos, garantindo, pelo consumo contínuo e crescente. o seu desenvolvimento c expansão, levando cm consideração os aspectos urbanos, regionais, culturais, econômicos e sociais de sua cxploração.

- Administração - instrumento que, em primeira c última instância, possibilita a gestão do negócio turístico propriamente dito, viabilizando a prestação dos serviços de transporte, alojamento, restauração, entretenimento c lazer ao consumidor final c garantindo o resultado esperado, que se traduz na respectiva remuneração e se justifica no lucro destes decorrente.

Como se vê, cmbora sendo impossível justificar-se a atividade turística sem o consórcio desses outros "instrumentos", também não se pode admitir nela prevalência de um sobre os demais. Por mais importante que scja um deles, o negócio do turismo não se realiza sem a capitancação administrativa, cscoltada por uma boa ação de marketing.

Foi com esse espirito que se instituiu e se consolidou esse curso na USP. Ainda assim, não raras vezes, a presença no corpo docente de um ou outro profissional de área complementar que, pelas mais diversas razões, pontificasse transitoriamente entre os demais, levou a momentâneos privilcgiamentos de algumas das áreas concias $\mathrm{cm}$ detrimento daquela que se $\mathrm{tem}$ consagrado como a "raiz forte do curso". Deve-se lembrar também que as chamadas atividades sociais de mercado, como o marketing, as relações públicas, a publicidade c administ ração, desenvolvem-se em função da produção de bens ou serviços que se dispõem ao consumo. Imaginar o contrário ć pura tolice.

Scja accito com maior ou menor intensidade, o curso de turismo também serviu para, sobremancira, fazer consolidar na universidade uma área de pósgraduação de cxpressiva accitação entre jovens, nem sempre oriundos da respectiva formação profissional. Mas isto só se deu graças ao empenho dos professores que compõem a estrutura curricular antecedentc. Há pouco menos de cinco anos, valendo-se do processo de repartição dos dois cursos de pós-graduação tradicionais da Escola de Comunicações c Artes, formularam o mestrado cm turisino e lazer.

Desnecessário será dizer que durante os anos cm que os dois cursos tradicionais prevaleceram para toda a cscola, os professores de turismo tinham no curso de pós-graduação cm Ciências da Comunicação a sua única via de acesso ao trabalho na pós-graduação. Além de ilógica, essa alternativa contribuía cm muito para ampliar a dependência ao campo da comunicação, de um núcleo de cnsino c pesquisa diferenciado pelas condições, já citadas, de sua natureza peculiar c especifica. Sem contar que os próprios alunos de graduação, nesses anos todos de existência do curso, não chegaram a consolidar uma identidade formatada segundo essa especificidade.

A constituição de uma pós-graduação especifica, entre outros benefícios, contribuiu para que se começasse a desenvolver um sentido próprio ao aprofundamento dos estudos na área. E bem verdade que a proximidade com as clações públicas, ou com a publicidade, já vinha contribuindo para sedimentar ampos de pesquisa de duplo interesse. Como cxemplo, podem ser citadas as esquisas onde se correlacionam turismo e relações públicas. Ferramenta de harketing, esta última também se aplica ao desenvolvimento do negócio turístico nquanto mecanismo de atendimento, referencial de pesquisa junto à clientela, uporte de planejamento estratćgico c, sobretudo, argumento de inovação.

Alguns estudos sobre turismo sob a ótica da administração c a função de clações públicas, que tratam o turista como um consumidor específico, já garaniram uma relação substancial de publicações em periódicos especializados, que convertem a importância da atividade econômica cm dados necessários ao desenrolvimento social. Os resultados, que não são poucos, revelam fatos de notória mportância. O turista, personagem principal desse processo, enseja o conhecimeno de definições psicológicas de alguém que, fragilizado pela transmigração 
espacial, necessita ser estudado muito alćm do seu aspecto "consumidor". $\mathrm{O}_{\mathrm{u}}$ então, de alguém cuja capacidade cconômica de demanda vai além de sua função de mero consumidor. Ou, ainda, de quem se lança às transmigrações espaciais, muito mais instado por fantasias que se associam à sua raiz cultural, do que por um simples impulso de consumo.

Nesse sentido, tem-se verilicado uma atividade intensa de convênios c outras inicitivas, todas clas voltadas à troca de informações c cxperiĉncias na árca. Entre 1993 c 1995, por cxemplo, celcbraram-se mais tratados com universidades c centros de estudos curopcus, asiáticos c nortcamericanos, com o propósito de intercambiar resultados de pesquisa, professores c publicações. Vários têm sido os docentes a participar de eventos, no país e no Exterior, apresentando trabalhos, dirigindo mesas redondas, discutindo os rumos da prolissão c do campo de trabalho. Tudo isso, como se quer, converte-se cm patrimônio, cujo verdadeiro sentido se expressa pelo desenvolvimento do turismo como atividade de mercado, como objeto de estudo, como justificativa para a transmigração espacial eventual de grandes contingentes de pessoas, como objeto de divisas produzidas para o país.

Vale a pena encarar essa realidade apesar dacríticas, dos desentendimentos, da incompreensão c do preconceito. Até mesmo para que um dia se reverta essa situação, conquistando o cstudo do turismo a mesma importância que têm outras áreas na Universidade. 